$15^{\text {th }}$ International Conference on

AEROSPACE SCIENCES \& AVIATION TECHNOLOGY,

$\boldsymbol{A S A T}$ - 15 - May 28 - 30, 2013, Email: asat@ mtc.edu.eg,

Military Technical College, Kobry Elkobbah, Cairo, Egypt,

Tel: +(202) 24025292 -24036138, Fax: +(202) 22621908

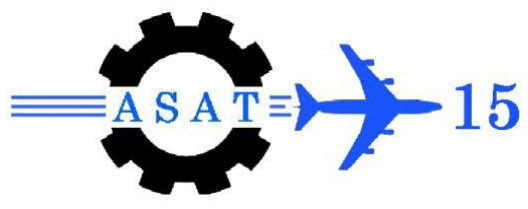

\title{
Numerical Analysis for Ferro Cement Panels Resisting Projectile Penetration with Different Initial Velocities
}

\author{
$\{\text { M.S. Zahran*, N.H. Abd elmataal, M. M. Abd elwahab, E. Eltehawy }\}^{\dagger}$
}

\begin{abstract}
Resistance to penetration by high velocity projectiles through concrete target is an essential design parameter for fortification structures. Due to the expensive costs of field test experiments, numerical modeling is considered one of the most efficient procedures to predict the response of concrete panels under the effect of impact loads. The change in strain rate influences the material behavior. Studying this behavior needs experimental test.

In this study, the experimental work is conducted to record the penetration depth through the concrete panels using the bullet at the industry. Two different panels are tested. Each panel has a different arrangement in the ferrocement layers. The finite element analysis (FEA) is used to model the concrete panels subjected to the penetration of the bullet. The results obtained by the FEA are compared with those obtained by the experimental work to verify the proposed finite element model.

Different initial velocities of the projectile are set to study the response of the target. The penetration depth and the strain energy are compared for each panel. The difference between the penetration depth and the strain energy, can describe the influence of the strain rate on the target behavior. The performance of the concrete panel reinforced by the ferrocement is improved to reduce the penetration of the bullet.
\end{abstract}

Keywords: Numerical analysis; ferrocement; projectile penetration.

\section{Introduction}

In defense applications, concrete is used as a structural member for runways, fortifications, command bunkers and hardened shelters [1]. Concrete is well known for its high compressive strength and low tensile strength compared with steel [1]. This combination of concrete and steel serves to enhance the overall bending strength of concrete. In many defense agencies, the complex interaction of a projectile with concrete has a great interest to both civil engineers and weapon designers [1].

In this computing age, the proliferation of faster and cheaper computing power is beginning to allow numerical simulation to play a more dominant role in predicting complex interaction of projectile with concrete [2]. With hydrocode simulation becoming a popular tool, complementing full-scale testing, an understanding of the constitutive models becomes pertinent [2].

This paper aims to introduce different systems for ferrocement concrete panels. The geometric shape of the ferrocement mesh changed in each panel group, which may affect the penetration resistance of the concrete panels. This paper employs the explicit dynamic finite element code 3D- AUTODYN to analyze the behavior of ferrocement concrete panels during projectile penetration at different initial velocities.

mz_mohamedzahran@yahoo.com

Egyptian Armed Forces, Egypt. 


\section{Experimental Program}

The experimental tests are divided into two phases; the first phase is used to measure the mechanical properties of the used concrete mix and the second phase is used to record the penetration depth in the tested panels.

\subsection{Material Properties}

\section{(a) Concrete}

The normal concrete mixture (N.C) is considered to be $350-\mathrm{kg} / \mathrm{m}^{3}$ cement, $1400-\mathrm{kg} / \mathrm{m}^{3}$ Dolomite, $700-\mathrm{kg} / \mathrm{m}^{3}$ sand, and $175-\mathrm{kg} / \mathrm{m}^{3}$ water, $\mathrm{W} / \mathrm{C}=0.5$. Table 1 presents the mechanical properties of the used concrete.

Table 1 Mechanical properties of the used concrete

\begin{tabular}{c|c|c|c|c|c|c}
\hline \multirow{2}{*}{ specimen } & \multicolumn{3}{|c|}{ Compressive strength $\left(\mathrm{kg} / \mathrm{cm}^{2}\right)$} & \multicolumn{2}{c}{ Mechanical properties } \\
\cline { 2 - 7 } & 3 days & 7 days & 28 days & 90 days & $\begin{array}{c}(\text { ఠ) specific } \\
\text { weight }\left(\mathrm{kg} / \mathrm{m}^{3}\right)\end{array}$ & $\begin{array}{c}(\text { E) Young's } \\
\text { modulus }\left(\mathrm{kg} / \mathrm{cm}^{2}\right)\end{array}$ \\
\hline N.C. & 212 & 277 & 307 & 350 & 2360 & 324789 \\
\hline \hline
\end{tabular}

\section{(b) Ferrocement Mesh}

The dimensions and the mechanical properties of the used expanded metal mesh are summarized in Table 2. [8]

Table 2 Dimensions and the mechanical properties of used expanded metal mesh

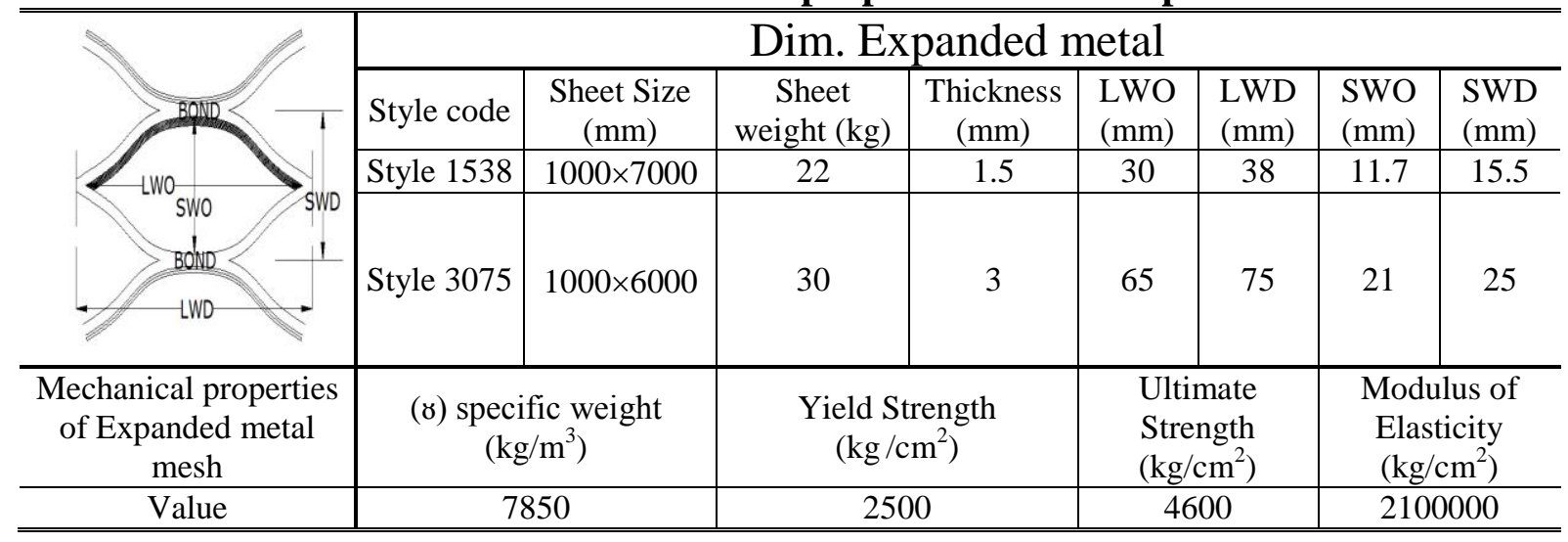

\subsection{Tested Specimens}

The specimens Dimensions were chosen from some previous researches [3, 4]. All concrete panels have the same dimensions $(500 \times 500 \times 200 \mathrm{~mm})$ as shown in Fig.1. There are four groups of specimens, the group is defined consist of two adjacent panels as shown in Fig.1. Each group is subjected to identical tests to record the laboratory results. The first group is defined as a plain concrete (SC). The second group is defined as a square honeycomb slab with cover (S.HC.C.) as shown in Fig.2. The third group is defined as a square honeycomb slab without cover (S.HC.) as shown in Fig.3.The fourth group is defined as a slab reinforced with square box (S.C.C), this group has been set numerically only to make a comprehensive study in the used panels. Table 3 describes all groups' details. 


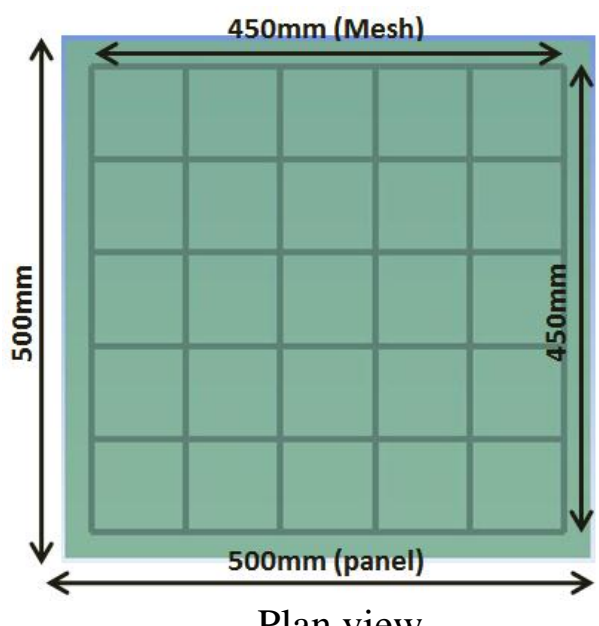

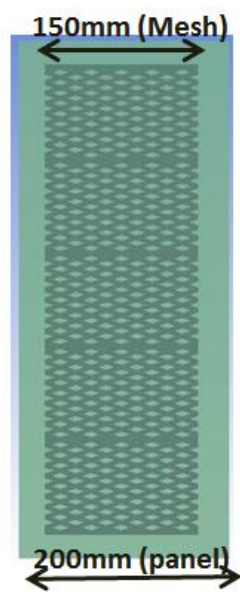

Side view

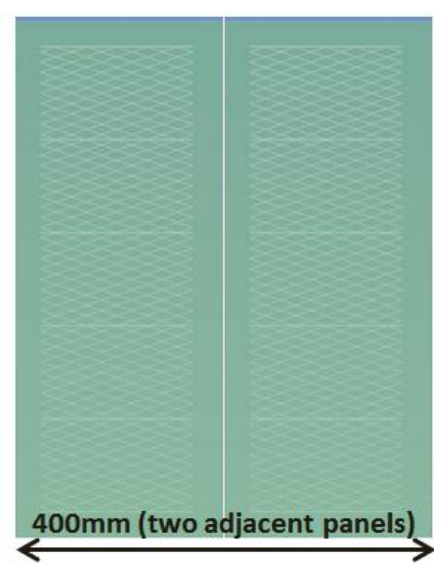

Group

Fig.1 Dimensions of concrete panels

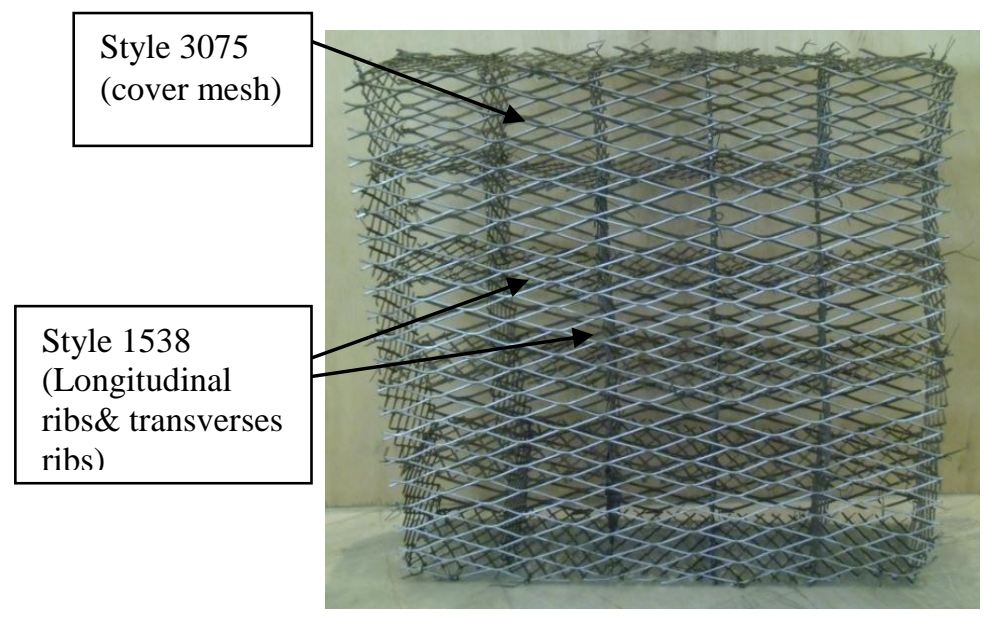

Fig.2. Ferrocement mesh of S.HC.C.

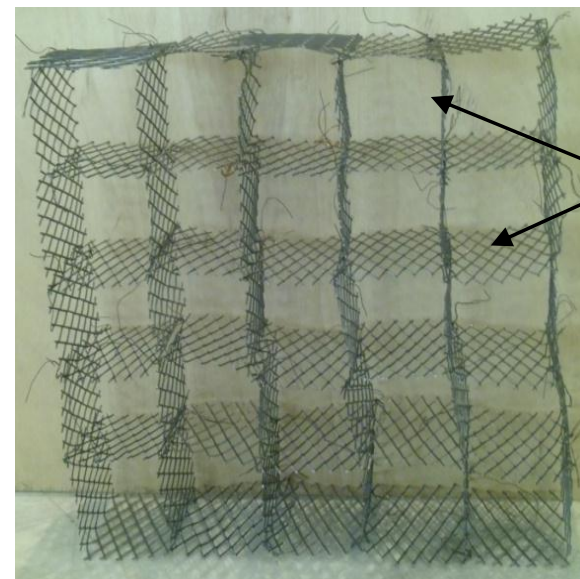

Style 1538

(Longitudinal

ribs\& transverses

ribs)

Fig. 3 Ferrocement mesh S.HC.

\subsection{Experiment Procedure}

The Gas gun tests were carried out to investigate the penetration resistance of concrete specimens opposed to ballistic impact (very high velocity of missile $=980 \mathrm{~m} / \mathrm{s}$ ) as shown in Figs. $(4,5)$. 
Table 3 Experimental specimens and new numerical model details.

\begin{tabular}{|c|c|c|c|c|c|c|c|}
\hline \multirow[b]{2}{*}{ NO. } & \multirow[b]{2}{*}{$\begin{array}{c}\text { Group } \\
\text { abbreviation }\end{array}$} & \multirow[b]{2}{*}{$\begin{array}{l}\text { Total thickness } \\
\text { \& reinforcement }\end{array}$} & \multirow[b]{2}{*}{ Description } & \multicolumn{4}{|c|}{ Reinforced meshes arrangement } \\
\hline & & & & Top & $\begin{array}{c}\text { Longit- } \\
\text { udinal } \\
\text { Middle }\end{array}$ & $\begin{array}{l}\text { Trans- } \\
\text { verse } \\
\text { Middle } \\
\end{array}$ & Bottom \\
\hline 1 & SC & $\begin{array}{l}40 \mathrm{~cm} \text { plain } \\
\text { concrete }\end{array}$ & $\begin{array}{l}2 \text { slabs } \times 20 \mathrm{~cm} \\
\text { control slab }\end{array}$ & & & & \\
\hline 2 & S.HC.C. & $\begin{array}{l}40 \text { cm ferro- } \\
\text { cement }\end{array}$ & $\begin{array}{c}2 \text { slabs } \times 20 \mathrm{~cm} \\
\text { reinforced with } \\
\text { square honeycomb } \\
\text { and cover }\end{array}$ & & & & \\
\hline 3 & S.HC. & $\begin{array}{l}40 \text { cm ferro- } \\
\text { cement }\end{array}$ & $\begin{array}{c}2 \text { slabs } \times 20 \mathrm{~cm} \\
\text { reinforced with } \\
\text { square honeycomb } \\
\text { without cover }\end{array}$ & & & Styl & \\
\hline 4 & S.C.C. & $\begin{array}{l}40 \mathrm{~cm} \text { ferro- } \\
\text { cement }\end{array}$ & $\begin{array}{l}\text { Numerical only- } \\
2 \text { slabs } \times 20 \mathrm{~cm} \\
\text { reinforced with } \\
\text { square Box }\end{array}$ & $\begin{array}{c}1 \text { layer } \\
\text { (style } \\
3075)\end{array}$ & $\begin{array}{c}2 \text { layer } \\
\text { (style } \\
1538)\end{array}$ & $\begin{array}{c}2 \text { layer } \\
\text { (style } \\
1538)\end{array}$ & $\begin{array}{c}1 \text { layer } \\
\text { (style } \\
\text { 3075) }\end{array}$ \\
\hline
\end{tabular}
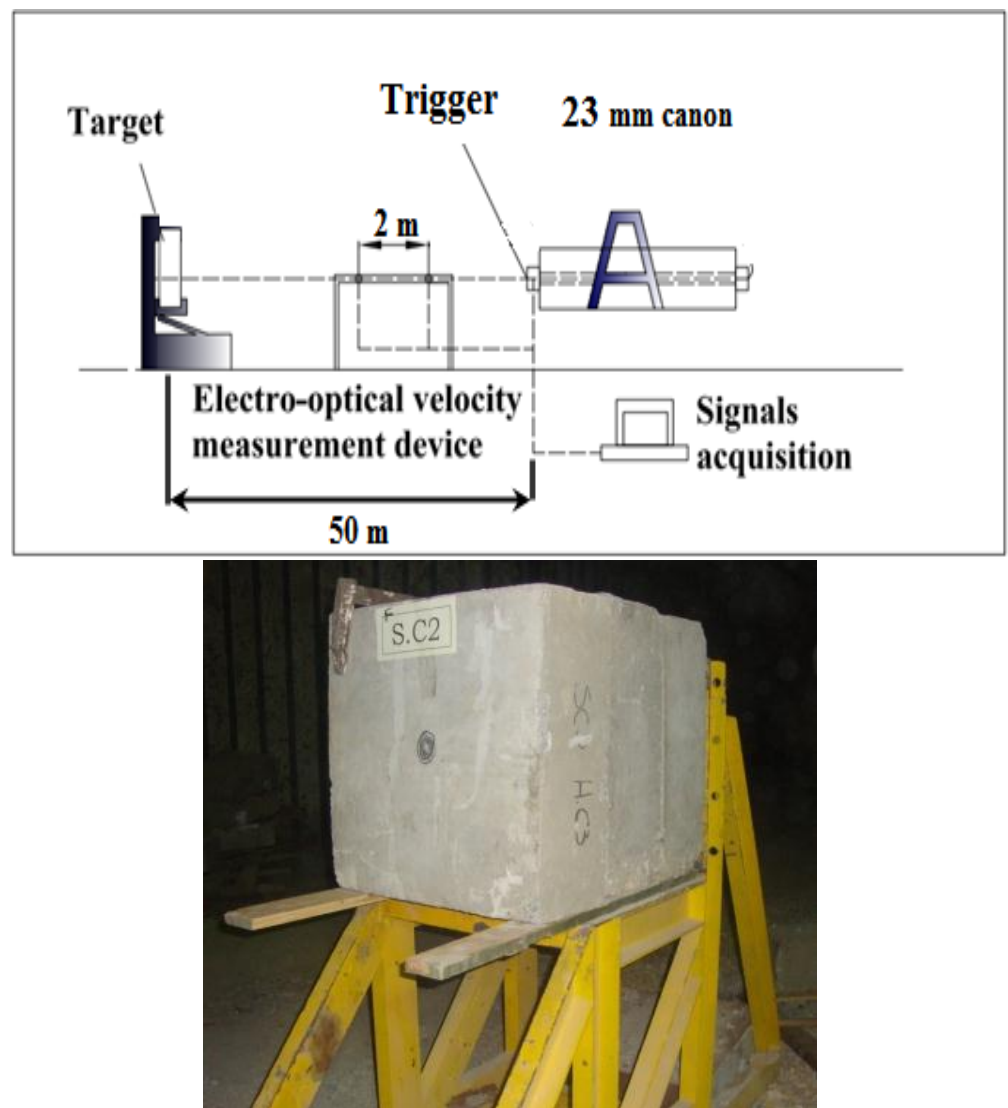

Fig.4 Penetration resistance test rig. 

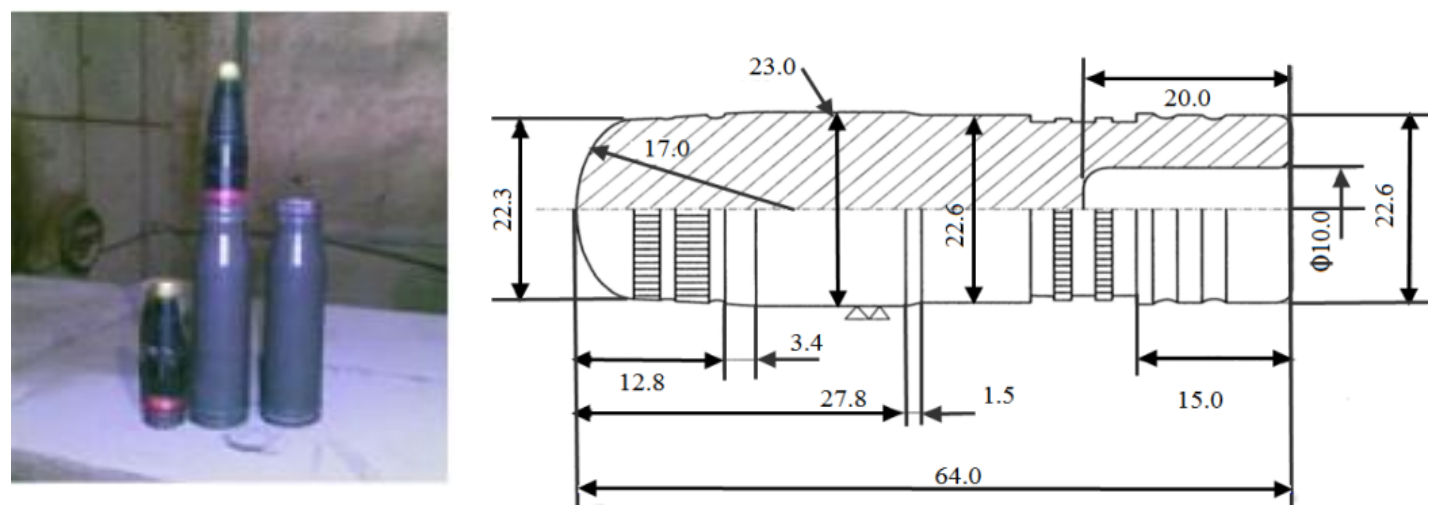

Fig. 5 Dimensions of $23 \mathrm{~mm}$ API Missile

\section{Numerical Validation}

The constitutive equation of AUTODYN package used for this penetration problem as it deals with the high strain rate problems [5]. The used subroutine for the concrete, and the projectile were Lagrange [5], but for the expanded metal mesh, it is necessary to use the Beam subroutine to obtain this complicated shape. The strength equations used for concrete are RH Concrete [6] and for metal Johnson Cook [7]. Three virtual strain gauges were used to calculate the effective-strain (EFF. STN) for each model [5], the location of these strain gauges as shown in Fig (6) and their coordinates refer to the origin of the penetration point $(0,0)$ are as follows in Table 4.

Table 4 The Virtual strain gauge locations

\begin{tabular}{l|c|c|c}
\hline \multicolumn{1}{c|}{ Gauge No. } & Gauge \#1 & Gauge \#2 & Gauge \#3 \\
\hline X Coordinate $(\mathrm{mm})$ & $50 \mathrm{~mm}$ & $100 \mathrm{~mm}$ & $150 \mathrm{~mm}$ \\
\hline Y Coordinate $(\mathrm{mm})$ & $50 \mathrm{~mm}$ & $100 \mathrm{~mm}$ & $150 \mathrm{~mm}$ \\
\hline Z Coordinate $(\mathrm{mm})$ & $175 \mathrm{~mm}$ & $175 \mathrm{~m}$ & $175 \mathrm{~mm}$ \\
\hline \hline
\end{tabular}

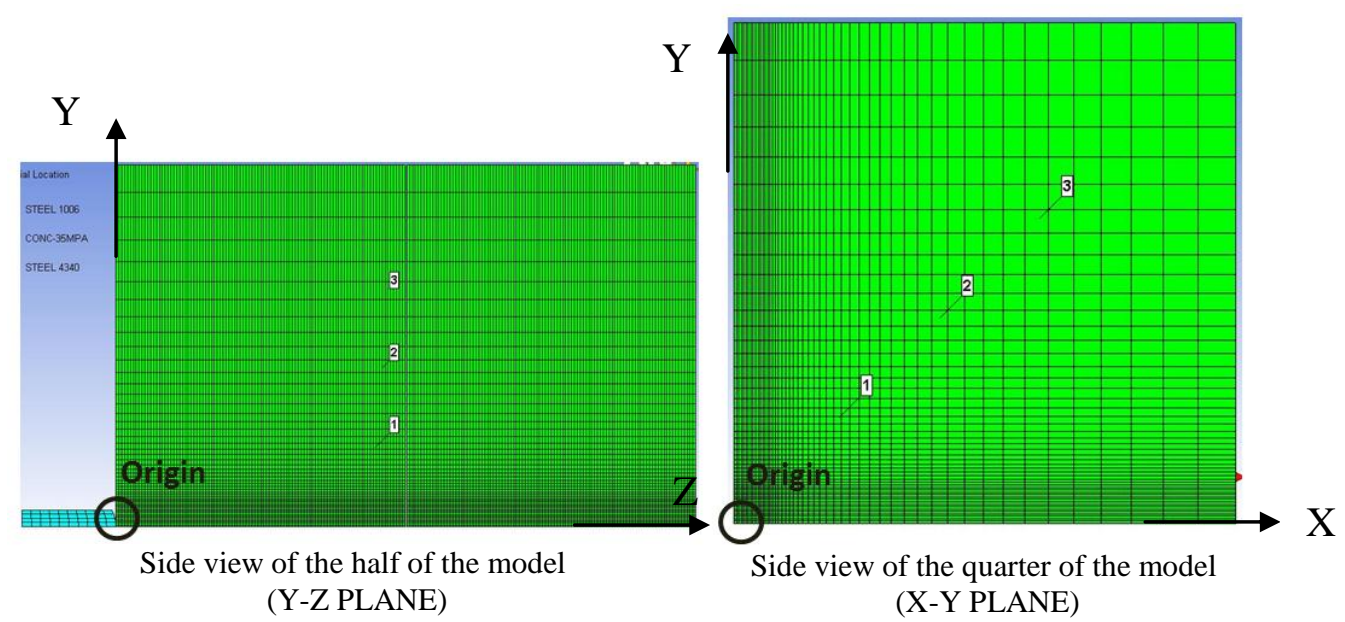

Fig.6 The locations of the virtual strain gauges 


\section{Numerical Update}

After using the constitutive equations in the present problem to verify the experimental measurements new input initial condition has been set; the new initial condition introduces a decrease in the projectile velocity at fixed percentage reduction. The changing in the velocity called to transfer the problem from the high velocity toward the intermediate velocity problem, and that aim to study the behavior of these combined targets under different conditions. The new input velocity is used in numerical analysis are: $784 \mathrm{~m} / \mathrm{s}(80 \%$ of ordinary velocity), $588 \mathrm{~m} / \mathrm{s}$ (60\% of ordinary velocity) and $392 \mathrm{~m} / \mathrm{s}$ (40\% of ordinary velocity).

\section{Experimental and Numerical Results}

Unfortunately two results of the nine tests were not captured due to an experimental error. The results, measurements, and the specimen's description of the tests will be stated compared with the numerical results as shown in Table (5).

Selected photos of the tests are shown in Fig. (7). The charts in Fig.(8) shows the calculation of the virtual strain gauges for the effective-strain parameter, values of Gauge \#2 gives an intermediate value between \#1 and \#3 so it will not give more than confirming the problem calculations. Table (6) shows the peak value of the EFF.STN and the maximum penetration depth.
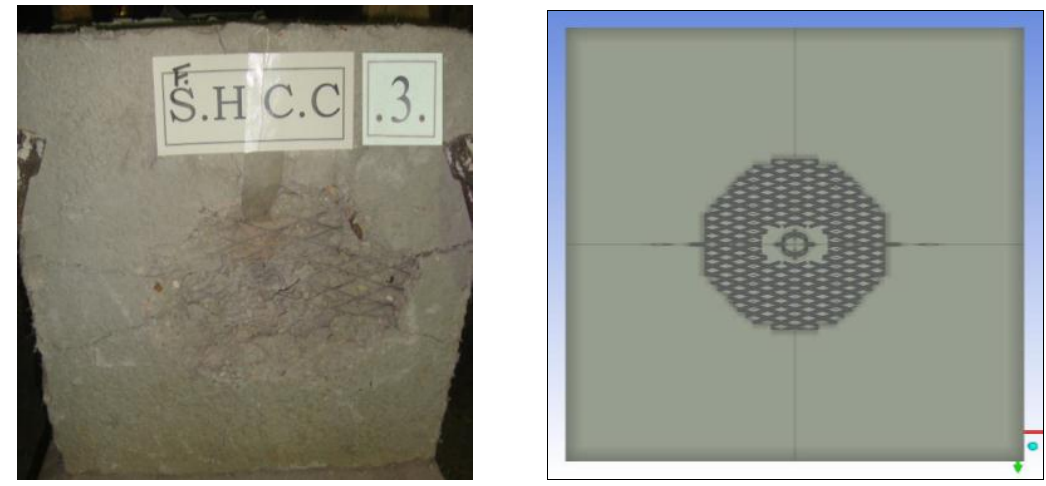

Fig.7 Numerical and experimental photo of S.HC.C .3. Front after shooting

\section{Analysis of Test Results}

It is observed from Table (5) that colored contours, (which represent the effective strain value) intense around the horizontal meshes like in S.HC.C and S.C.C but there is no appearance for this intensity in S.HC panel, which means that the horizontal mesh is the mean barrier for the projectile velocity. Some colored splotches appear in S.HC.C, which mean that the load transfer to the Vertical square honeycomb meshes, otherwise in S.HC. there is no appear for this splotches although it has the same vertical honeycomb meshes. The splotches disappeared due to no existence of the horizontal barrier to transfer the load or even to resist the projectile. The penetration depth almost the same with S.HC.C and S.C.C, therefore adding the vertical barriers to the horizontal barriers will not make a significant effect in such this problem conditions. This combination as in S.HC.C. would lead to expensive use with material, however using the horizontal mesh gives the best influence on the penetration depth. 
The Charts in Fig (8) show that Gauge \#3 always has the upper hand in the EFF. STN value, this value infers to stress transformation not absorption. This means that the square honeycomb reinforcements transfer the strain to the panel boundary. This transaction leads to make the square honeycomb reinforcement is better to be used with the distributed loads, generally it deals with a global deformations problem better than local one, and the preset study is introducing a very concentrated local deformation problem.

\section{Table 5 Numerical and experimental results}
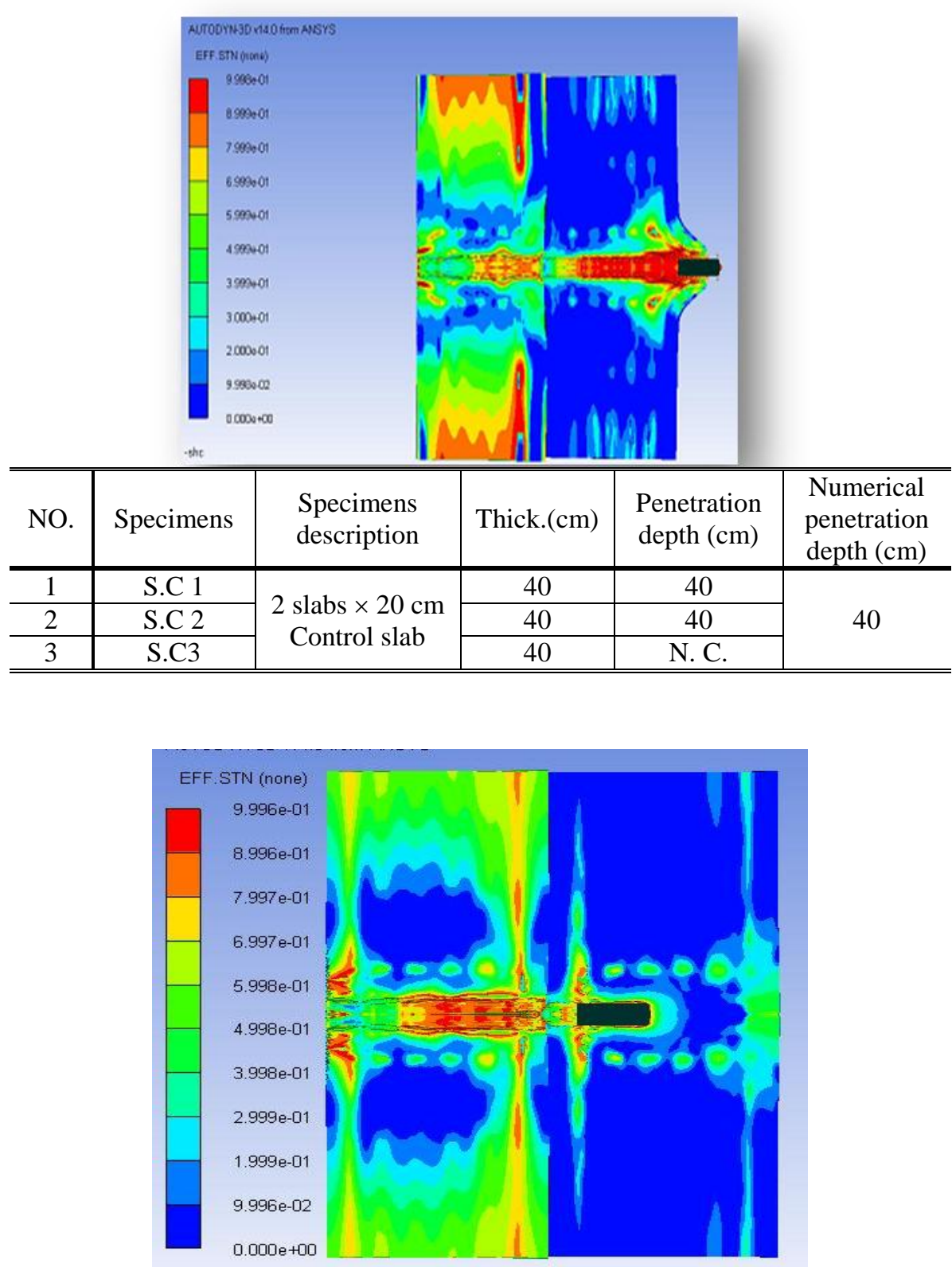

\begin{tabular}{|c|c|c|c|c|c|}
\hline NO. & Specimens & Specimens description & $\begin{array}{l}\text { Thick. } \\
(\mathrm{cm})\end{array}$ & $\begin{array}{l}\text { Penetration } \\
\text { depth }(\mathrm{cm})\end{array}$ & $\begin{array}{l}\text { Numerical } \\
\text { penetration } \\
\text { depth }(\mathrm{cm})\end{array}$ \\
\hline 1 & S.HC.C.1 & \multirow{3}{*}{$\begin{array}{c}2 \text { slabs } \times 20 \mathrm{~cm} \\
\text { Reinforced with square } \\
\text { honeycomb cover }\end{array}$} & 40 & 29.6 & \multirow{3}{*}{29.3} \\
\hline 2 & S.HC.C. 2 & & 40 & 27.3 & \\
\hline 3 & S.HC.C.3 & & 40 & 28.1 & \\
\hline
\end{tabular}


Table 5 (continued) Numerical and experimental results
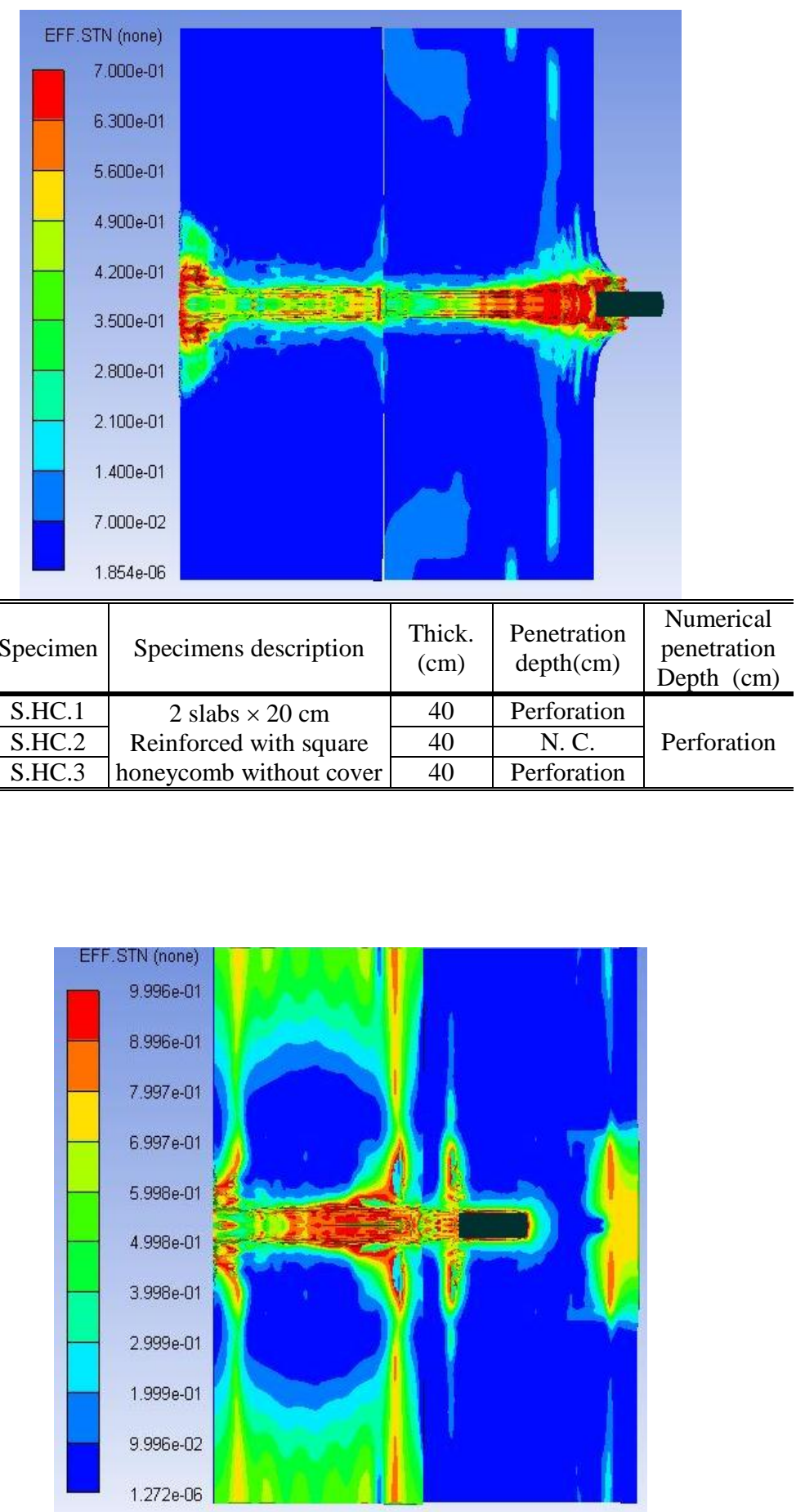

\begin{tabular}{c|c|c|c|c|c}
\hline \hline NO. & specimens & $\begin{array}{c}\text { Specimens } \\
\text { description }\end{array}$ & $\begin{array}{c}\text { Thick. } \\
(\mathrm{cm})\end{array}$ & $\begin{array}{c}\text { Penetration } \\
\text { depth }(\mathrm{cm})\end{array}$ & $\begin{array}{c}\text { Numerical } \\
\text { penetration } \\
\text { Depth }(\mathrm{cm})\end{array}$ \\
\hline 1 & S.C.C & $\begin{array}{c}2 \text { slabs } \times 20 \mathrm{~cm} \\
\text { reinforced with box }\end{array}$ & 40 & $\begin{array}{c}\text { No experimental } \\
\text { test }\end{array}$ & 30.9 \\
\hline \hline
\end{tabular}




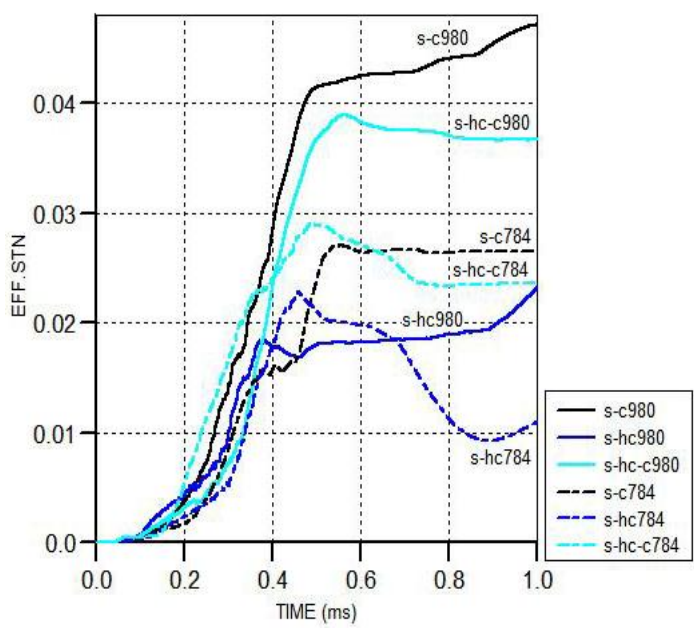

(a) Gauge \#1 for velocity $980-784 \mathrm{~m} / \mathrm{s}$

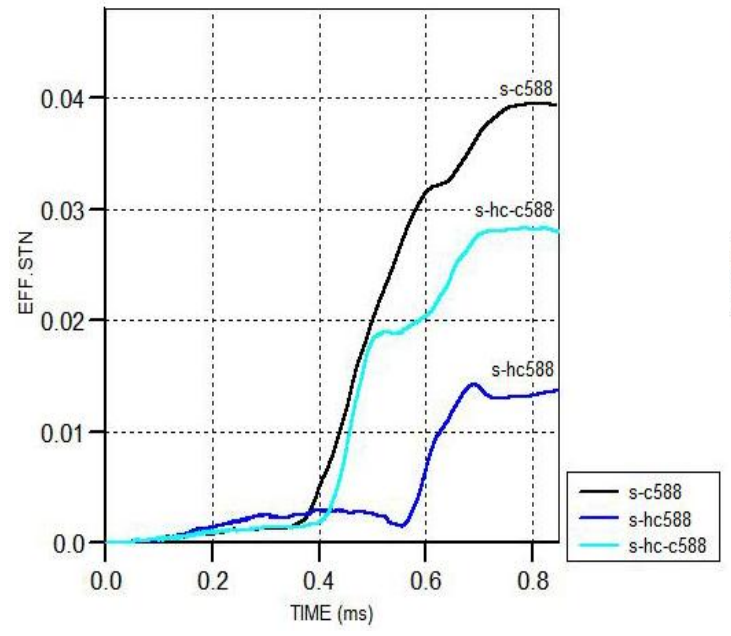

(C) Gauge \#1 for velocity $588 \mathrm{~m} / \mathrm{s}$

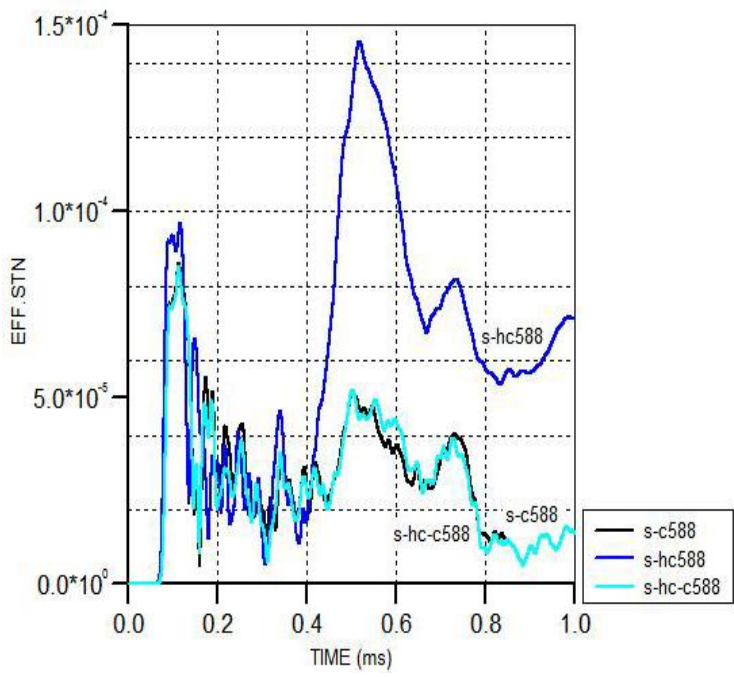

(E) Gauge \#3 for velocity $588 \mathrm{~m} / \mathrm{s}$

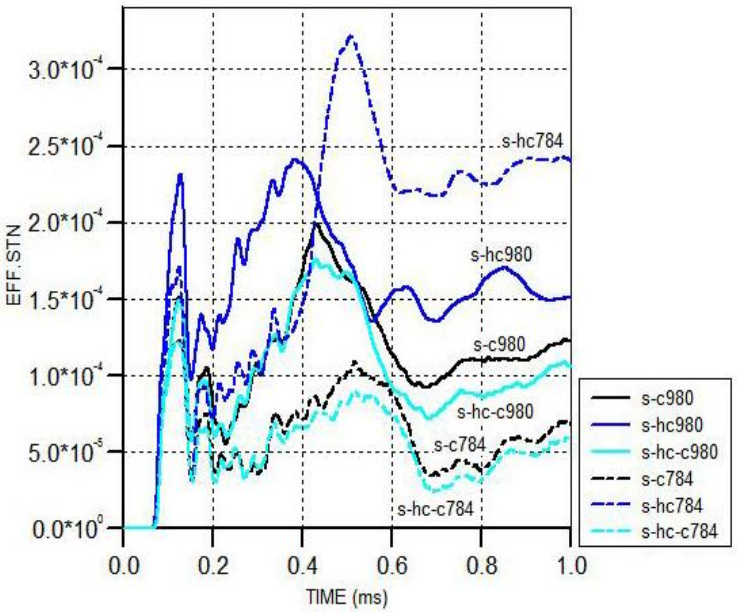

(b) Gauge \#3 for velocity $980-784 \mathrm{~m} / \mathrm{s}$

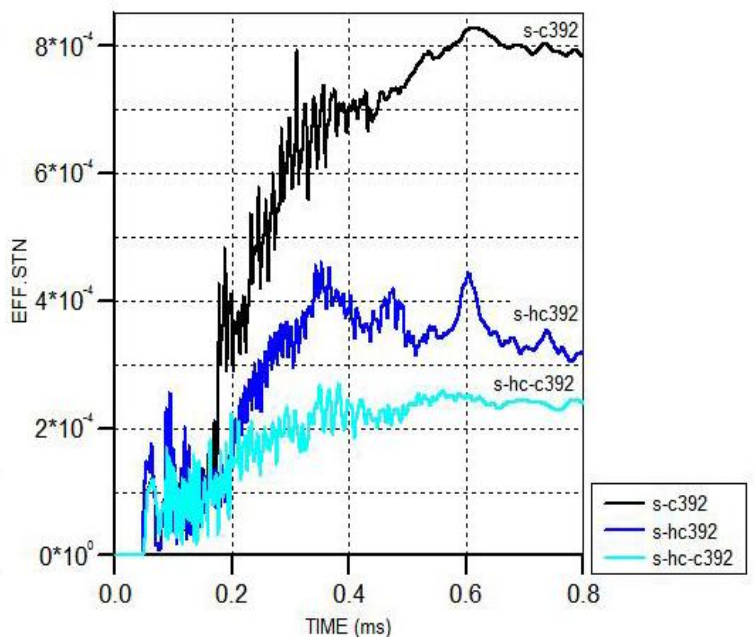

(D) Gauge \#1 for velocity $392 \mathrm{~m} / \mathrm{s}$

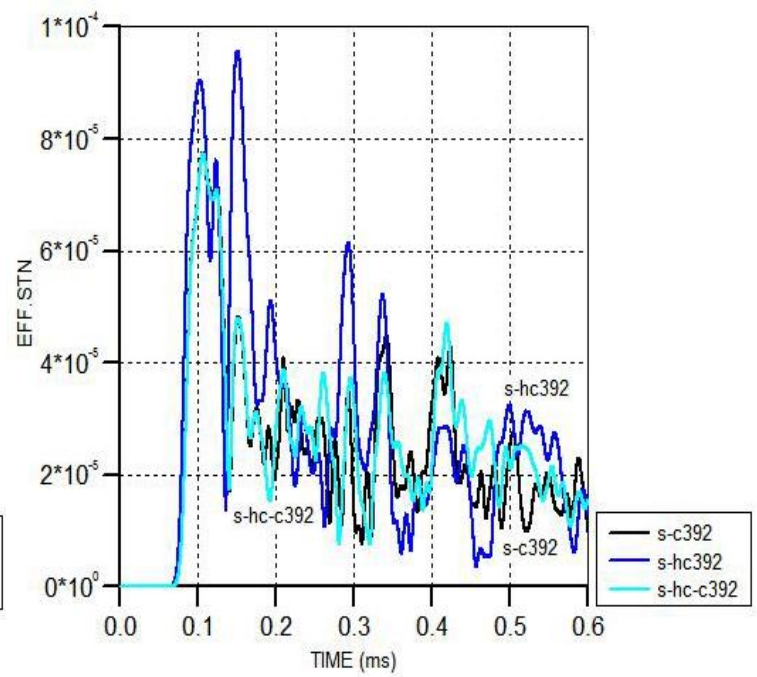

(F) Gauge \#3 for velocity 392m/s

Fig.8 The Effective-Strain time history for the ferrocement panels. 
Table 6 Maximum values of the penetration depths and effective-strains for each initial velocity

\begin{tabular}{c|c|c|c|c|c|c|c|c|c}
\hline \hline \multirow{2}{*}{ Int. Velocity } & \multicolumn{3}{|c|}{ Gauge \#1 Eff. Strain } & \multicolumn{3}{c|}{ Gauge \#3 Eff. Strain } & \multicolumn{3}{c}{ Penetration Depth (mm) } \\
\cline { 2 - 11 } & S.HC.C & S.HC & S.C.C & S.HC.C & S.HC & S.C.C & S.HC.C & S.HC & S.C.C \\
\hline $980 \mathrm{~m} / \mathrm{s}$ & $3.9 \mathrm{E}-2$ & $3.7 \mathrm{E}-2$ & $4.7 \mathrm{E}-2$ & $1.8 \mathrm{E}-4$ & $2.4 \mathrm{E}-4$ & 2E-4 & 290.3 & Per. & 308.8 \\
\hline $784 \mathrm{~m} / \mathrm{s}$ & $2.9 \mathrm{E}-2$ & $2.3 \mathrm{E}-2$ & $2.7 \mathrm{E}-2$ & $1.2 \mathrm{E}-4$ & $3.2 \mathrm{E}-4$ & $1.2 \mathrm{E}-4$ & 239.8 & 306.2 & 246 \\
\hline $588 \mathrm{~m} / \mathrm{s}$ & $2.8 \mathrm{E}-2$ & $1.4 \mathrm{E}-2$ & $3.9 \mathrm{E}-2$ & $8.5 \mathrm{E}-5$ & $1.5 \mathrm{E}-4$ & $8.6 \mathrm{E}-5$ & 200.5 & 233.3 & 200.9 \\
\hline $392 \mathrm{~m} / \mathrm{s}$ & $2.7 \mathrm{E}-4$ & $4.6 \mathrm{E}-4$ & $8.3 \mathrm{E}-4$ & $7.7 \mathrm{E}-5$ & $9.6 \mathrm{E}-5$ & $7.6 \mathrm{E}-5$ & 100.6 & 134.4 & 105.5 \\
\hline \hline
\end{tabular}

\section{Conclusions}

The study summarized results of nine panel specimens and four numerical models subjected to impact of a $23 \mathrm{~mm}$ API Missile. The parameters investigated include reinforcement schemes of the panels. From the results of the experimental investigations which reported, the following conclusions could be drawn as follows:

- The constitutive equations on AUTODYN Package verify the reinforced concrete with expanded metal mesh.

- Using ferrocement barriers parallel to the projectile path (square honeycomb only like S.HC) leads to results like plain concrete in the high velocity impact problem, regarding that the projectile did not face the vertical meshes.

- Using ferrocement barriers perpendicular to the projectile path (like S.HC.C and S.C.C) leads to a significant influence in the penetration depth. Also it decreases flying in the concrete fragments.

- The interior dimensions for each cell in ferrocement mesh should be less than the projectiles yield. The square honey comb reinforcement gives a significant effect with the global deformation problems.

\section{References}

[1] J. Leppanen, "Dynamic Behavior of concrete Structures subjected to Blast and Fragment Impacts," 2002.

[2] S. o. E. a. E. Institute for Infrastructure and Environment, University of Edinburgh, Edinburgh EH9 3JL, UK, "Evaluation of typical concrete material models used in hydrocodes for high dynamic response simulations," International Journal of Impact Engineering, 2009.

[3] Abdullah, KatsukiTakiguchi, Koshiro Nishimura, Shingo Hori "Behavior of Ferrocement Subjected to Missile Impact" Tokyo Institute of Technology, Japan, Structural Mechanics in Reactor Technology (SMiRT 17), Paper \# J04-7.

[4] C. Y. Tham, "Reinforced concrete perforation and penetration simulation usingAUTODYN-3D," Computational Mechanics Division , Institute of High Performance Computing, 1 Science Park Road, \#01-01 The Capricorn, Singapore Science Park II, Singapore 117528, 2005.

[5] A. AUTODYN, "Mechanical (formerly Simulation)," TUTORIAL, November 2009.

[6] Engng. Frac. Mech. Vol 21. No. 1.pp 31-48. 1985 Johnson\& Cook

[7] Riedel W. "Betonunter dynamischenLasten" Phd Thesis.EMI.Freiburg. Germany. 2000

[8] Multi M Group for metallic an wooden industries (BUILDING PRODUCTS). 